\title{
Genome-wide analyses identify transcription factors required for proper morphogenesis of Drosophila sensory neuron dendrites
}

\author{
Jay Z. Parrish, ${ }^{1}$ Michael D. Kim, ${ }^{1}$ Lily Yeh Jan, and Yuh Nung Jan ${ }^{2}$ \\ Departments of Physiology and Biochemistry, Howard Hughes Medical Institute, University of California, \\ San Francisco, California 94143, USA
}

\begin{abstract}
Dendrite arborization patterns are critical determinants of neuronal function. To explore the basis of transcriptional regulation in dendrite pattern formation, we used RNA interference (RNAi) to screen 730 transcriptional regulators and identified $\mathbf{7 8}$ genes involved in patterning the stereotyped dendritic arbors of class I da neurons in Drosophila. Most of these transcriptional regulators affect dendrite morphology without altering the number of class I dendrite arborization (da) neurons and fall primarily into three groups. Group A genes control both primary dendrite extension and lateral branching, hence the overall dendritic field.

Nineteen genes within group $A$ act to increase arborization, whereas 20 other genes restrict dendritic coverage. Group B genes appear to balance dendritic outgrowth and branching. Nineteen group B genes function to promote branching rather than outgrowth, and two others have the opposite effects. Finally, 10 group $\mathrm{C}$ genes are critical for the routing of the dendritic arbors of individual class I da neurons. Thus, multiple genetic programs operate to calibrate dendritic coverage, to coordinate the elaboration of primary versus secondary branches, and to lay out these dendritic branches in the proper orientation.
\end{abstract}

[Keywords: Transcription; RNAi; Drosophila; neuron; dendrite]

Supplemental material is available at http://www.genesdev.org.

Received November 18, 2005; revised version accepted February 1, 2006.

An important problem in nervous system development is how neurons achieve the proper wiring pattern. At the level of a single neuron, the axon projection pattern and dendrite arborization pattern are two critical determinants of neuronal circuitry. Whereas much attention has focused on elucidating basic mechanisms governing axon development, relatively little is known about the genetic programs required for the establishment of dendrite arborization patterns that are hallmarks of distinct neuronal types.

The complex developmental processes involved in dendrite morphogenesis have profound functional implications (Jan and Jan 2003). Following the specification of a neurite as dendrite rather than axon, a dendrite must make critical decisions about when, for how long, and in what direction it will grow, as well as when and where to form branches. The resulting dendrite arborization patterns of a neuron determine the number and arrange-

\footnotetext{
${ }^{1}$ These authors contributed equally to this work. ${ }^{2}$ Corresponding author.

E-MAIL yuhnung.jan@ucsf.edu; FAX (415) 476-5774.

Article published online ahead of print. Article and publication date are at http://www.genesdev.org/cgi/doi/10.1101/gad.1391006.
}

ment of its sensory or synaptic inputs, the extent of segregation of inputs impinging on a dendritic branch or a subdomain of the dendritic arbor, and the way a neuron integrates and processes its inputs (Magee 2000). Therefore it is important to understand how the dendritic branch number, distribution, and length can be controlled during development.

The Drosophila peripheral nervous system (PNS) provides a model for systematic analysis of dendrite morphogenesis. The PNS is comprised of several neuronal types including dendrite arborization (da) neurons, multidendritic (md) neurons that are born by mid-embryogenesis and innervate the epidermis (Bodmer et al. 1987). Da neurons can be divided into distinct classes (I-IV) based on their dendrite arborization pattern (Grueber et al. 2002). These da neurons are a suitable model for dissecting dendrite growth, branching, and class-specific specification/arborization because of their stereotyped dendritic pattern. Furthermore, different classes of da neurons may function in distinct sensory modalities, including thermosensation, nociception, and larval locomotion (Ainsley et al. 2003; Liu et al. 2003; Tracey et al. 2003), raising the possibility that features of dendrite arborization could be correlated with specific behaviors. 
Class I neurons have simple and stereotyped dendritic arbors. Three class I neurons are present in each abdominal hemisegment and two of these, $\mathrm{ddaD}$ and ddaE, are located dorsally, whereas the other, vpda, is located ventrally. ddaD and ddaE each elaborate a single primary dendrite that grows dorsally before generating one or two additional primary branches. Subsequently, secondary branches grow laterally, roughly perpindicular to the primary branches (Sugimura et al. 2003). By the end of embryogenesis, the dendritic arbor of class I neurons is stabilized, and very little dynamic behavior is evident at later developmental stages. Dorsal class I neurons occupy distinct regions of the hemisegment with ddaD sending its arbors dorsally and anteriorly, while ddaE arborizes an equivalent area posterior to ddaD (Grueber et al. 2002). Dendritic arbors from ddaD and ddaE normally do not come into contact, suggesting that intrinsic/extrinsic guidance cues target their dendritic arbors to specific receptive fields. These class I da neurons therefore provide a platform for the identification of genes that control dendrite growth, branching, and routing and for the placement and spacing of dendritic fields of individual da neurons.

In the vertebrate spinal cord, a Sonic hedgehog-regulated transcriptional cascade of homeodomain transcription factors (TFs) directs differentiation of specific neuronal subtypes (Ericson et al. 1997; Briscoe et al. 2000). Motorneurons in the spinal cord are organized in columns with distinct columnar sets of motorneurons innervating different targets, and this columnar organization is regulated by a Hox (homeobox) gene transcriptional regulatory network (Dasen et al. 2003, 2005). Likewise, LIM homeodomain TFs are required to establish the columnar identity of motorneurons and control type-specific axon projection patterns (Jessell 2000; Shirasaki and Pfaff 2002). When the axons of motorneurons arrive in the vicinity of their targets, induction of ETS family TFs such as Pea3 is required for proper axon-terminal projection and arborization (Livet et al. 2002). Similarly, TFs have important functions in neuronal differentiation in Drosophila. During Drosophila photoreceptor neuron development, runt, the founding member of the runx class of TFs, is required for lamina/ medulla axon target choice (Kaminker et al. 2002), and the POU domain TF acj6 is required for Drosophila olfactory receptor neuron axon targeting (Komiyama et al. 2004). Therefore, multiple aspects of neuronal development and differentiation are transcriptionally regulated.

Although the mechanisms underlying dendrite development are still largely unknown, evidence supporting an important role for transcriptional regulation is emerging. In the Drosophila PNS, the zinc-finger TF hamlet regulates a binary choice of cell fates between a neuron with a single unbranched dendrite and a multiple-dendrite neuron, the TF sequoia, which is related to the transcriptional repressor tramtrack, regulates dendrite outgrowth, and the BTB/POZ domain TF abrupt and homeodomain TF cut regulate dendrite arborization and branching (Gao et al. 1999; Brenman et al. 2001; Moore et al. 2002; Grueber et al. 2003a; Li et al. 2004; Sugimura et al. 2004). Furthermore, some TFs that regulate neurogenesis in mammals, including Notch1 and NeuroD, have been shown to function in dendrite morphogenesis, demonstrating that some TFs may function at multiple steps in neuron differentiation (Redmond et al. 2000; Gaudilliere et al. 2004). Finally, calciumresponsive dendrite growth requires the TF CREST in the mouse cortex and hippocampus, demonstrating that transcriptional regulation underlies activitydependent dendritic growth (Aizawa et al. 2004). With these examples illustrating the significant roles of transcription regulation in dendrite morphogenesis, one expects that a systematic analysis of TF function should provide insight into multiple aspects of dendrite development.

Traditionally, loss-of-function screens in Drosophila have relied on genetic mutants or chromosome aberrations, but such approaches, while extremely valuable, are sometimes complicated by maternal rescue of mutant phenotypes, redundant gene functions, and the time required to achieve saturation mutagenesis. The use of RNA interference (RNAi) to reduce target gene function provides a solution to many of these difficulties and has proven invaluable in Caenorhabditis elegans in the analysis of basic aspects of cell and developmental biology (Poulin et al. 2004). Two recent screens for genes that function in Drosophila embryonic heart development and nervous system development demonstrate the potential application of RNAi screens in the study of organ development in Drosophila (Ivanov et al. 2004; Kim et al. 2004).

The importance of transcriptional regulation in a broad range of developmental programs, including neuronal morphogenesis, prompted us to investigate the roles of transcriptional regulators in dendrite development. We have carried out an RNAi screen to identify transcriptional regulators that control and coordinate various aspects of dendrite arborization of Drosophila class I da neurons. Our results demonstrate that TFs regulate multiple distinct aspects of dendrite development. First, transcriptional regulators can either promote or inhibit dendrite arborization, suggesting that antagonistic functions of TFs regulate arborization patterns. Second, some TFs have opposing actions on dendrite growth and branching, suggesting that dendritic branching programs partly entail limiting primary branch extension. Third, routing of class I dendrites is regulated by TFs, suggesting that directed outgrowth of dendrites involves transcriptionally regulated attractive and/or repulsive signaling. Finally, certain TFs not only regulate class I neuron number but may serve additional function in dendrite morphogenesis. These findings provide a framework for transcriptional regulation of dendrite morphogenesis for one neuronal type. Our study also reveals the identity and possible function of genes that may regulate vertebrate neuronal morphogenesis since most of the genes we have identified are conserved genes with no previously known function in dendrite development. 


\section{Results}

Class I da neurons are amenable to RNAi-based analysis of dendrite morphogenesis

To assay for the stereotyped dendrite arborization pattern of class I da neurons (hereafter referred to as class I neurons) in RNAi-based analysis of dendrite development, we have used a previously described Gal4 enhancer trap line $\left(G_{a 14^{221}}\right)$ that is highly expressed in class I neurons and weakly expressed in class IV neurons during embryogenesis (Grueber et al. 2003a). Because of the simple and stereotyped dendritic arborization patterns of ddaD and ddaE, we have focused our studies of dendrite development on these two dorsally located class I neurons.

To establish that RNAi is an efficient method to systematically study dendrite development in the Drosophila embryonic PNS, we first demonstrated that injecting embryos with double-stranded RNA (dsRNA) for green fluorescent protein $(g f p)$, but not nonspecific RNA or buffer alone, is sufficient to attenuate Gal-4 $4^{221}$-driven expression of an mCD8 : GFP fusion protein as measured by confocal microscopy (Fig. 1B,C). Next we tested whether RNAi could efficiently phenocopy loss-of-function mutants known to affect dendrite development. Similar to the mutant phenotype of short stop (shot), which encodes an actin/microtubule cross-linking protein, shot(RNAi) caused routing defects, dorsal overextension, and a reduction in lateral branching of dorsally extended primary dendrites (Fig. 1D,E). Likewise, RNAi of sequoia or flamingo resulted in overextension of ddaD
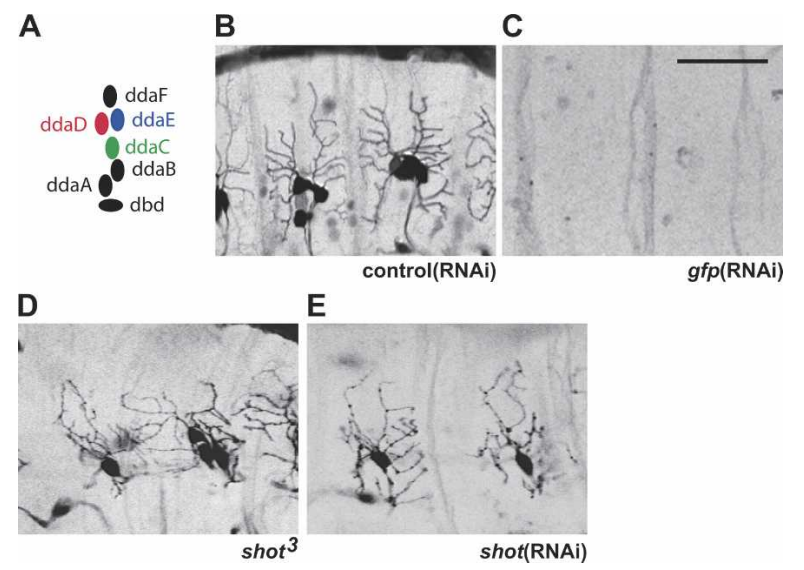

Figure 1. RNAi effectively reduced target gene expression in class I da neurons. (A) Schematic of the dorsal da neurons of the Drosophila PNS. The class I neurons, ddaD and ddaE, are represented by red and blue ovals, respectively, while the class IV neuron, ddaC, is represented by a green oval. Anterior is left and dorsal is up in all figures. $(B, C)$ Live image of Gal4 ${ }^{221}$, UASmCD8GFP embryo injected with buffer control $(B)$ or GFP dsRNA $(C)$. Gal4 ${ }^{221}$ is expressed at higher levels in ddaE than $\mathrm{ddaD}$, sometimes resulting in weak labeling of ddaD. $(D, E)$ Live image of class I dendrites marked by GFP expression driven by Gal4 $^{221}$ in $s h o t^{3}$ homozygous mutant $(D)$ and embryo injected with shot dsRNA (E). Bar, $25 \mu \mathrm{m}$. and ddaE, RNAi of hamlet resulted in supernumerary class I neurons, and RNAi of tumbleweed resulted in supernumerary class I neurons and a range of arborization defects (data not shown), consistent with the reported mutant phenotypes (Gao et al. 1999; Brenman et al. 2001; Moore et al. 2002; Goldstein et al. 2005). Thus, RNAi is effective in generating reduction of function phenotypes in embryonic class I dendrites.

\section{RNAi screening uncovers novel regulators of dendrite development}

To systematically test the function of TFs in dendrite morphogenesis, we generated a library of dsRNAs covering 730 regulators of transcription, injected dsRNAs individually or in a variety of combinations, and assayed for phenotypes blind to the identity of the injected dsRNA(s) (Supplementary Table S1). Without methods to systematically assess the degree of knockdown of target gene expression, it was not possible to establish a quantitative index of phenotypic effects. Therefore we focused our attention on qualitative analysis of phenotypes. As a safeguard against false positives, candidates were chosen for further analysis only after yielding dendrite phenotypes in multiple blind tests. Finally, these candidates have been characterized using multiple independent markers for different cell types, including other neuronal types, muscle and epidermis to assess the neuronal specificity of the RNAi phenotype (Table 1).

RNAi of candidate genes yielded discrete classes of phenotypes affecting branch length, branch number, dendrite arborization pattern, and neuronal number. From multiple independent rounds of RNAi screening (see below), we isolated 76 transcriptional regulators that affect class I dendrite morphogenesis (Table 1). These genes fall into three main functional groups: genes that promote or inhibit arborization by regulating dendrite outgrowth and branching, genes that have opposing functions on dendrite outgrowth and branching, and genes that function in the routing of class I dendrites.

\section{Group A TFs that promote arborization through concerted regulation of outgrowth and branching}

We have identified a group of transcriptional regulators, group A, that controls the size of the dendritic field of class I neurons. RNAi of 19 TFs resulted in reduction of the field size covered by ddaD and ddaE (Table 1). A reduction of coverage could be the result of a net reduction in dendrite outgrowth, branching, or both. As shown in Figure 2, group A TFs have effects on both primary dendrite growth and secondary dendrite growth. For example, RNAi of the PAS-domain TF trachealess (trh) caused a minor reduction in both primary branch outgrowth and the number of lateral branches and a more marked reduction in the overall length of lateral branches (Fig. 2B). Consequently, the most distal regions of the dendritic field, especially the regions covered by lateral branches, are not innervated. By contrast, RNAi 
Table 1. RNAi phenotypes of candidate TFs that regulate dendrite morphogenesis in class I da neurons

\begin{tabular}{|c|c|c|c|c|c|}
\hline & & \multicolumn{2}{|c|}{ Group B } & \multirow{4}{*}{$\frac{\text { Group C }}{\text { Misrouting }}$} & \multirow{4}{*}{$\frac{\text { Cell no. }}{\text { Decreased }}$} \\
\hline \multicolumn{2}{|c|}{ Group A } & \multirow{3}{*}{$\begin{array}{l}\text { Increased } 1^{\circ} \text { branch } \\
\text { extension; reduced } \\
\text { lateral branching }\end{array}$} & \multirow{3}{*}{$\begin{array}{l}\text { Reduced } 1^{\circ} \text { branch } \\
\text { extension; increased } \\
\text { lateral branching }\end{array}$} & & \\
\hline Reduced & Increased & & & & \\
\hline arborization & arborization & & & & \\
\hline Bap55 a,d & Abrupt $^{\mathrm{a}, \mathrm{c}, \mathrm{d}, \mathrm{f}}$ & $\operatorname{Bigmax}^{\mathrm{a}, \mathrm{d}}$ & $\mathrm{Gcm} 2^{\mathrm{d}}$ & Bap55 $5^{\mathrm{a}, \mathrm{d}}$ & Ato $^{\mathrm{c}, \mathrm{d}}$ \\
\hline CG $1244^{\mathrm{d}}$ & $\operatorname{Adf} 1^{\mathrm{d}, \mathrm{f}}$ & CG1884 $4^{\mathrm{a}, \mathrm{d}}$ & Pcaf $^{\mathrm{a}, \mathrm{d}}$ & Bap60 $60^{\mathrm{a}, \mathrm{c}, \mathrm{d}}$ & $\mathrm{Ci}^{\mathrm{a}, \mathrm{b}, \mathrm{c}, \mathrm{d}}$ \\
\hline CG1841 $1^{\mathrm{a}, \mathrm{d}}$ & Aop $^{\mathrm{a}, \mathrm{c}, \mathrm{d}, \mathrm{f}}$ & CG7056 ${ }^{\mathrm{d}}$ & & $\mathrm{Brm}^{\mathrm{a}, \mathrm{c}, \mathrm{d}, \mathrm{e}}$ & Sens ${ }^{\mathrm{c}, \mathrm{d}, \mathrm{f}}$ \\
\hline CG2678 & $\operatorname{Arc} 42^{1,4}$ & Groucho $^{4,6}$ & & CG $1244^{4}$ & $\mathrm{Zf} 30 \mathrm{c}^{3}$ \\
\hline CG2 $2808^{\mathrm{a}, \mathrm{d}}$ & Asf $1^{\mathrm{a}, \mathrm{d}}$ & $\mathrm{Kni}^{\mathrm{a}, \mathrm{b}, \mathrm{d}}$ & & CG17118 & Increased \\
\hline CG5684 $4^{\mathrm{a}, \mathrm{d}}$ & Bon $^{c, d, f}$ & $\mathrm{~L}(3) \mathrm{mbt}^{\mathrm{a}, \mathrm{d}}$ & & CG4328 ${ }^{\mathrm{d}}$ & $\operatorname{Acf} 1^{a, b, c, d}$ \\
\hline $\mathrm{D} 4^{\mathrm{a}, \mathrm{d}}$ & Caf- $1^{\mathrm{a}, \mathrm{c}, \mathrm{d}}$ & $M b f 1^{d}$ & & CG $7417^{d}$ & CG53433, \\
\hline $\mathrm{EcR}^{\mathrm{a}, \mathrm{c}, \mathrm{d}, \mathrm{f}}$ & CG2808 & $\operatorname{Med} 21^{\mathrm{a}, \mathrm{d}}$ & & CG9104 ${ }^{\mathrm{d}}$ & CG8495 \\
\hline Ets $21 C^{d}$ & CG5684 $4^{\mathrm{a}, \mathrm{d}}$ & Runt $^{\mathrm{d}}$ & & $P t x 1^{d}$ & $\mathrm{Chm}^{\mathrm{c}, \mathrm{d}}$ \\
\hline $\mathrm{Fd} 3 \mathrm{f}^{\mathrm{d}}$ & $\mathrm{Dpn}^{\mathrm{d}, \mathrm{f}}$ & Sens ${ }^{\mathrm{c}, \mathrm{d}, \mathrm{f}}$ & & Sens ${ }^{c, d, f}$ & $\mathrm{Jumu}^{\mathrm{a}, \mathrm{c}, \mathrm{d}, \mathrm{f}}$ \\
\hline $\mathrm{HmgD}^{\mathrm{a}, \mathrm{d}}$ & $E(b x))^{d, f}$ & $\operatorname{Sin} 3 \mathrm{a}^{\mathrm{a}, \mathrm{c}, \mathrm{d}, \mathrm{f}}$ & & & Nerfin- $1^{\mathrm{c}, \mathrm{d}}$ \\
\hline$M 7^{c, d}$ & Elongin $\mathrm{C}^{\mathrm{d}, \mathrm{f}}$ & $\operatorname{Sirt} 2^{\mathrm{d}}$ & & & $\mathrm{Sqz}^{\mathrm{a}, \mathrm{c}, \mathrm{d}, \mathrm{e}}$ \\
\hline$M 8^{\mathrm{c}, \mathrm{d}, \mathrm{f}}$ & $\mathrm{Esc}^{\mathrm{a}, \mathrm{c}, \mathrm{d}, \mathrm{f}}$ & Snail ${ }^{\mathrm{a}, \mathrm{d}, \mathrm{f}}$ & & & \\
\hline $\mathrm{Mi}^{\mathrm{a}, \mathrm{d}}$ & $\mathrm{E}(\mathrm{z})^{\mathrm{a}, \mathrm{d}, \mathrm{f}}$ & $\operatorname{Snr} 1^{a, b, d, f}$ & & & \\
\hline Scrt ${ }^{\mathrm{d}, \mathrm{f}}$ & $\mathrm{E} 2 \mathrm{~F}^{\mathrm{a}, \mathrm{c}, \mathrm{d}, \mathrm{f}}$ & Taf $4^{\mathrm{a}, \mathrm{d}, \mathrm{f}}$ & & & \\
\hline $\mathrm{Sv}^{\mathrm{a}, \mathrm{c}, \mathrm{d}}$ & ISWI $^{\mathrm{a}, \mathrm{d}, \mathrm{f}}$ & Trap36 $6^{\mathrm{a}, \mathrm{d}}$ & & & \\
\hline $\operatorname{Tgo}^{\mathrm{a}, \mathrm{c}, \mathrm{d}, \mathrm{e}}$ & $\mathrm{Lbe}^{\mathrm{a}, \mathrm{c}, \mathrm{d}, \mathrm{f}}$ & Trap $100^{\mathrm{a}, \mathrm{d}, \mathrm{e}}$ & & & \\
\hline $\operatorname{Trh}^{\mathrm{a}, \mathrm{d}, \mathrm{e}}$ & $\mathrm{Nvy}^{\mathrm{a}, \mathrm{d}, \mathrm{f}}$ & $\mathrm{Ttk}^{\mathrm{c}, \mathrm{d}, \mathrm{f}}$ & & & \\
\hline $\mathrm{Usp}^{\mathrm{a}, \mathrm{c}, \mathrm{d}, \mathrm{f}}$ & $\operatorname{Rpd} 3^{\mathrm{a}, \mathrm{d}, \mathrm{f}}$ & Wor ${ }^{\mathrm{d}, \mathrm{f}}$ & & & \\
\hline & $\mathrm{Su}(\mathrm{z}) 12^{\mathrm{a}, \mathrm{c}, \mathrm{d}, \mathrm{f}}$ & & & & \\
\hline
\end{tabular}

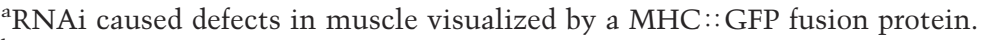

${ }^{b}$ RNAi caused defects in the epidermis as monitored by an Armadillo::GFP fusion protein.

${ }^{\mathrm{c}} \mathrm{RNAi}$ caused alterations in the number of MD neurons labeled by the pan-MD marker Gal4 ${ }^{109(2) 80}$.

${ }^{\mathrm{d}} \mathrm{RNAi}$ caused defects in dendrite morphogenesis visualized with Ga14 ${ }^{109(2) 80}$.

${ }^{\mathrm{e}}$ Mutant allele(s) of the candidate gene cause no obvious defects in da dendrite development.

${ }^{\mathrm{f}}$ Mutant allele(s) of the candidate gene cause reproducible defects in da dendrite development.

of genes such as the zinc-finger TF pygopus or the BTB/ POZ-domain TF cg1841 caused more severe reduction of primary branch outgrowth as well as lateral branching and lateral branch length, resulting in a more drastic reduction of receptive field (Fig. 2C,D). In an extreme case, RNAi of the high mobility group gene $h m g D$ resulted in an almost complete block of primary dendrite extension and lateral branching (Fig. 2E). In general, the genes with the most severe effects on primary branch outgrowth also have the most severe effects on branching, suggesting that these genes may function to regulate dendritic arborization overall.

Although the genes in this class all caused qualitatively similar defects in arborization, some notable phe-
A

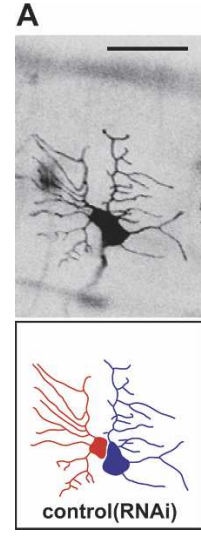

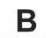

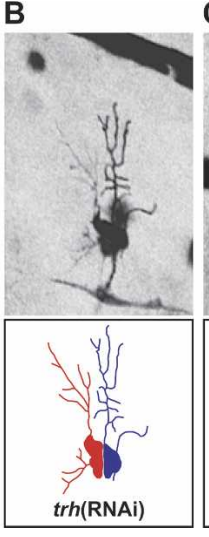

C

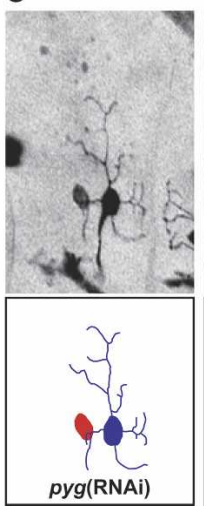

D

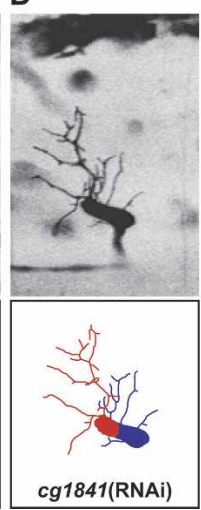

E

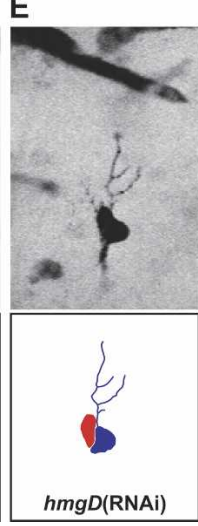

$\mathbf{F}$

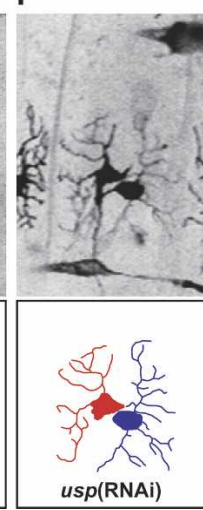

Figure 2. A subset of group A transcription factors function to promote dendrite arborization. (A-F) Live image and corresponding tracing of ddaD (red) and ddaE (blue) class I dendrites in Ga14 ${ }^{221}$, UAS-mCD8GFP embryos injected with buffer control (A), trh dsRNA $(B)$, pyg dsRNA $(C), \operatorname{cg} 1841$ dsRNA $(D), h m g D$ dsRNA $(E)$, or usp dsRNA $(F)$. In $C$ and $E$, the GFP signal in ddaD is not strong enough to permit unambiguous tracing of ddaD dendrites. Tracings are done to scale. Bar, $25 \mu \mathrm{m}$. 
notypic differences are suggestive of distinct functions for some of these genes in regulating dendrite arborization. RNAi of the nuclear hormone receptors ultraspiracle (usp) and ecdysone receptor (EcR) significantly reduced primary dendrite outgrowth, but caused only modest reduction of lateral branching and lateral branch outgrowth, suggesting that branching is not absolutely dependent on proper outgrowth (Fig. 2F; Table 1). Since the Usp/EcR heterodimer is responsible for ecdysoneresponsive activation of transcription, as well as ligandindependent transcriptional repression, it is likely that these genes function together to promote dendrite outgrowth.

RNAi of many group A genes resulted in embryonic lethality at a significantly higher rate than control injections (data not shown). Thus, many of these genes are likely essential for embryonic development, either due to their involvement in regulating neuronal morphogenesis or due to other aspects of their functions.

\section{Group A transcriptional regulators that restrict dendrite arborization}

In addition to genes with functions in promoting dendrite arborization, we identified 20 group A genes that regulate dendrite arborization by limiting dendrite growth and/or branching. Consistent with recent reports that loss of function of the $\mathrm{BTB} / \mathrm{POZ}$ domain TF abrupt $(a b)$ causes an increase in dendritic branching and altered distribution of branches (Li et al. 2004; Sugimura et al. 2004), we found that $a b$ (RNAi) altered the arborization of class I dendrites. As shown in Figure 3B, $a b($ RNAi) caused an increase in the number and length of lateral branches, expanding the coverage field most noticeably along the anteroposterior (AP) axis. In addition to these defects, $a b$ (RNAi) also caused frequent cell death, consistent with the phenotype we observed for a hypomorphic allele of $a b$ (Supplementary Table S2).

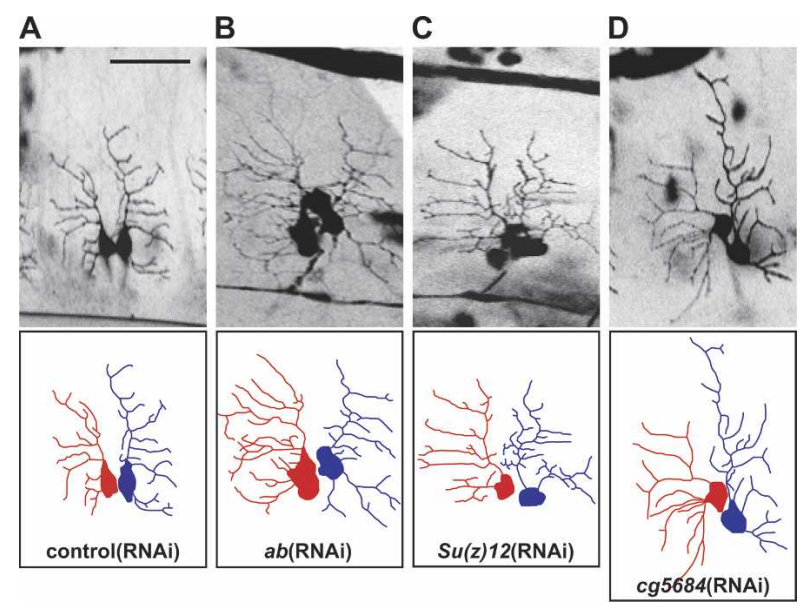

Figure 3. Some group A transcription factors normally limit dendrite arborization. $(A-D)$ Live image and corresponding tracing of GFP expressing class I dendrites in embryos injected with buffer control $(A), a b$ dsRNA $(B), \operatorname{Su}(z) 12$ dsRNA $(C)$, or cg5684 dsRNA $(D)$. Bar, $25 \mu \mathrm{m}$.
Increased dendritic branching also resulted from RNAi of several genes known to affect nervous system development, including Adh transcription factor 1 (Adf1), the zinc finger TF nervy (nvy), the basic helix-loop-helix (bHLH) TF deadpan (dpn), as well as genes not previously known to affect neuronal function, such as the putative transcription elongation factor Elongin $c$ (Table 1; Fig. 9, below). Both Adf1 and dpn mutants have defects in larval locomotion and, in light of recent findings suggesting that da neurons may regulate aspects of larval locomotion (Ainsley et al. 2003), it is possible that dendrite defects underlie these behavioral defects. Consistent with its role in class I dendrite development, $d p n$ is expressed in all PNS neurons (Bier et al. 1992). Likewise, nervy has been implicated in regulation of axon branching in motorneurons and is apparently expressed in most neurons (Feinstein et al. 1995; Terman and Kolodkin 2004). Thus, nervy likely regulates multiple aspects of neuronal differentiation. Finally, Elongin $C$ may regulate transcriptional elongation but also likely functions as a component of a multimeric protein complex that includes the von Hippel-Lindau (VHL) tumor suppressor and targets specific proteins for poly-ubiquitination and degradation (Shuin et al. 2004). Moreover, BTB/POZ domain proteins (such as $c g 1841$ and $a b$ ) function as substrate adaptors for cullin E3 ligases. Interestingly, RNAi of a Drosophila homolog (tango) of a known VHL substrate (HIF-1) also affected dendrite arborization (Table 1). It thus appears that protein degradation pathways regulate dendrite arborization.

RNAi of the Polycomb group (PcG) genes Su(z)12, E(z), esc, or Caf1 similarly caused an increase in branch number and an expansion of the receptive field of class I neurons (Fig. 3C; data not shown). Consistent with the similar RNAi phenotypes for these genes, $\operatorname{Su}(z) 12, E(z)$, esc, and Caf1 are components of the multiprotein esc/E(z) polycomb repressor complex. One critical role for PcGmediated gene silencing is the regulation of hox gene expression. Therefore, Polycomb-mediated regulation of hox gene expression likely contributes to arborization of class I neurons.

RNAi of several genes affected dendrite arborization primarily by causing an increase in dorsal and lateral dendrite extension without significantly affecting branch number (Table 1). For example, RNAi of the putative transcriptional repressor cg5684 caused dorsal overextension of the primary dendrite in $\mathrm{ddaE}$ and an overall increase in dendritic length in both $\mathrm{ddaD}$ and ddaE (Fig. 3D). In general, RNAi of genes that increased arborization rarely caused dendrites to cross the dorsal midline or segment borders, or increased branching more than twofold as compared with untreated neurons. It thus appears that dendritic outgrowth is further limited by neuronal growth capacity and/or other external constraints.

Group B TFs with opposing actions on dendrite outgrowth and branching shape dendrite arbors

In contrast to the genes that coordinately affect dorsal dendrite outgrowth and lateral branching/outgrowth, we 
identified a group of 21 genes (group B) that have opposing effects on dendrite outgrowth and branching, suggesting that dendrite outgrowth and branching might partially antagonize one another. RNAi of 19 of these genes resulted in dorsal overextension of primary dendrites and a reduction in lateral branching/lateral branch extension (Figure 4B-D; Table 1). In the most severe cases, such as RNAi of the transcriptional repressor snail, we observed dorsal overextension of almost completely unbranched dendrites (Fig. 4B). Like snail(RNAi), RNAi of the nuclear hormone receptor knirps, the transcriptional repressor $1(3) \mathrm{mbt}$, as well as 15 other genes, all caused dorsal overextension of primary dendrites (Fig. 4C,D; Table 1). As in the case of genes that normally limit arborization (Fig. 3), RNAi of these genes rarely caused dendrites to cross the dorsal midline.

In addition to the effects on primary dendrite extension, RNAi of each of these 18 genes limits the number and length of lateral dendrite branches. As mentioned above, RNAi of some genes such as snail or knirps almost completely blocked dendrite branching, whereas RNAi of other genes such $1(3) \mathrm{mbt}$ had more modest effects on dendrite branching. In addition, we noticed a significant reduction of branching at the distal tip of the dorsally projected primary dendrite. In control treated stage 17 embryos, branchpoints are distributed along the primary dendrite, with the most distal branchpoint usually located within a few microns of the distal tip of the dendrite (Fig. 4A). In contrast, branching is rarely observed within 10 microns of the distal dendritic tip following RNAi of these group B genes. In some cases, such as snail(RNAi), knirps(RNAi), or $1(3) m b t(R N A i)$, the most distal branchpoint is located 25 microns or further from the distal tip of the primary dendrite (Fig. 4B-D). Therefore, these TFs inhibit primary branch extension but promote lateral branching and lateral branch extension.
In addition to identifying a large class of TFs that inhibit primary branch extension and promote lateral branching, we have also found that TFs promote dendrite extension and limit dendrite branching. RNAi of two genes, glial cells missing 2 ( $\mathrm{gcm} 2)$ and the histone acetyltransferase pcaf, caused an increase in lateral branching and a marked reduction in dorsal extension of ddaE (Fig. $4 \mathrm{E}, \mathrm{F})$. Thus, transcriptional pathways exist that have opposing effects on primary branch outgrowth and secondary branching, suggesting that these processes may normally antagonize one another.

\section{Group C TFs regulate dendrite routing}

Proper dendritic routing is important for primary dendrites of ddaD and ddaE to grow in parallel toward the dorsal midline without crossing each other and for secondary branches of $\mathrm{ddaD}$ and $\mathrm{ddaE}$ to avoid the space between ddaD and ddaE (Fig. 5A). Therefore, there must be mechanisms that promote this stereotyped arborization pattern, including signals that promote anterior arborization of $\mathrm{ddaD}$ and posterior arborization of $\mathrm{ddaE}$, as well as signals that antagonize posterior arborization of $\mathrm{ddaD}$ and anterior arborization of ddaE. Indeed, RNAi of 10 TFs disrupted the dendritic routing patterns of ddaD and ddaE, resulting in aberrantly oriented primary dendrites (Fig. 5; Table 1). RNAi of cg1244, bap55 (brahma associated protein of $55 \mathrm{kD} \mid, \operatorname{cg} 9104, \mathrm{cg} 4328$, and $\operatorname{cg} 7417$ resulted in inappropriate anterior arborization of ddaE (Fig. 5B-E) as well as inappropriate posterior arborization of ddaD (Fig. 5F). We also observed anterior or even ventral displacement of ddaD concomitant with anterior arborization of ddaE (Fig. 5E) as well as displacement of ddaE arbors concomitant with misrouting of ddaD. Finally, reducing sens function by RNAi or genetic mutation caused extensive mixing of dendritic arbors from $\mathrm{ddaD}$ and ddaE, in addition to dorsal overextension of
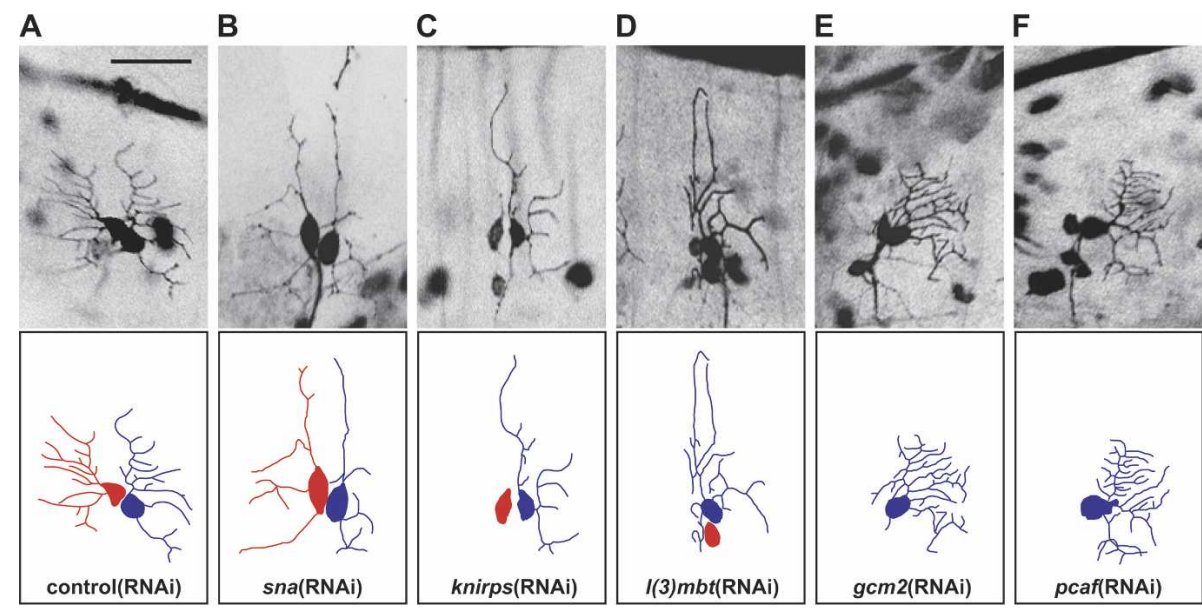

Figure 4. Group B transcription factors have antagonistic effects on primary dendrite growth and lateral branch extension. $(A-F)$ Live image and corresponding tracing of class I dendrites in embryos injected with buffer control $(A)$, sna dsRNA $(B)$, knirps dsRNA $(C)$, $1(3) m b t$ dsRNA $(D), g c m 2$ dsRNA $(E)$, or pcaf dsRNA $(F)$. In $A-D$, the cell bodies of ddaE are aligned in the traces below the images, allowing comparison of primary branch length. The neurite projecting ventrally from the dorsal border of the image in $B$ originates from an unidentified dorsally located ectopic neuron rather than a contralateral class I neuron, and is therefore not represented in the trace. Bar, $25 \mu \mathrm{m}$. 
Parrish et al.

A

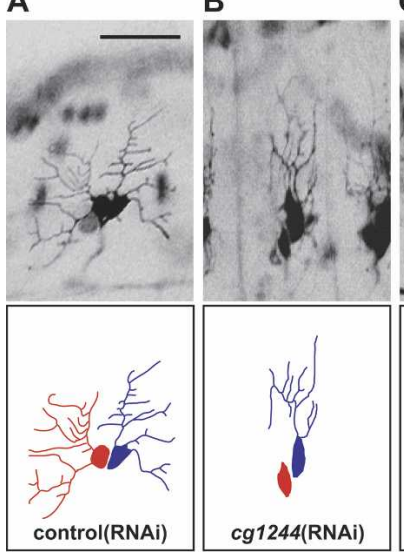

C

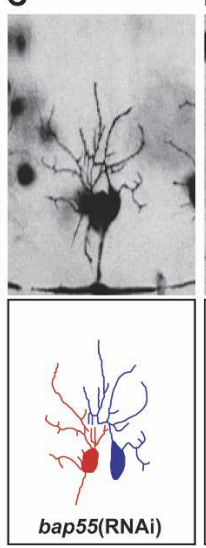

D

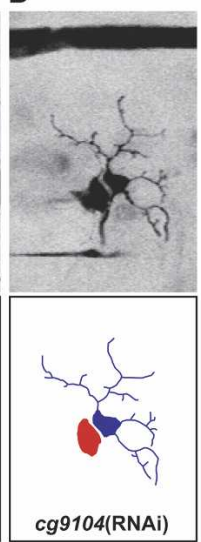

E

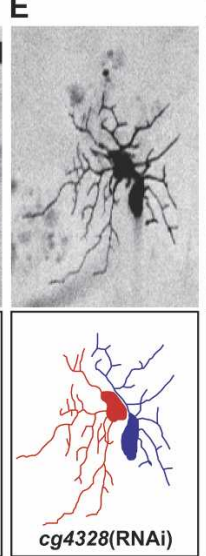

$\mathbf{F}$

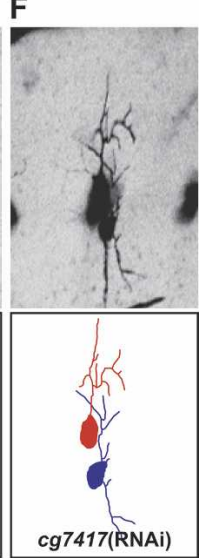

Figure 5. Group $\mathrm{C}$ transcription factors control the relative placement and orientation of class I dendrites. $(A-F)$ Live image and corresponding tracing of class I dendrites in embryos injected with buffer control $(A)$, cg1244 dsRNA (B), bap55 dsRNA (C), cg9104 dsRNA $(D), \operatorname{cg} 4328$ dsRNA $(E)$, or $\operatorname{cg} 7417$ dsRNA $(F)$. Bar, $25 \mu \mathrm{m}$.

primary dendrites and an overall reduction in the number of class I neurons (Fig. 8F, below).

It is also worth noting that RNAi treatment that caused reduced dendritic outgrowth often caused minor routing defects. For example, pyg(RNAi) or cg1841(RNAi) caused inappropriate routing of ddaE (Fig. 2C,D). The routing defects seen with these candidates may reflect a disruption of attractive/repulsive signaling that normally regulates dendrite arborization. The source of such signals is currently unknown, although of great interest.

TFs likely exert distinct mitotic and post-mitotic functions to regulate neuron morphogenesis

TFs play critical roles in neurogenesis, and some genes that regulate neurogenesis also affect post-mitotic neu- ronal differentiation. Because clones of duplicated class I neurons have wild-type dendrite arborization patterns, class I dendritic arbors appear to be insensitive to cell number defects (Grueber et al. 2003b). Indeed, dendrite arborization of class I neurons in embryos carrying the temperature-sensitive neurogenic mutation $\operatorname{Notch}^{t s}\left(N^{t s}\right)$ is unaffected by as much as a fivefold increase in class I neuron number (Fig. 6A-D), and is likely insensitive to multiplication of other da neurons as well since our $N^{t s}$ experiments caused increased numbers of other da neurons (data not shown). Furthermore, in cases where only one of the class I neurons is multiplied, the dendrites of neighboring class I neuron are unaffected (Fig. 6B). On the other hand, laser ablation of ddaD or $\mathrm{ddaE}$ or the occasional cell loss caused by RNAi of various genes did
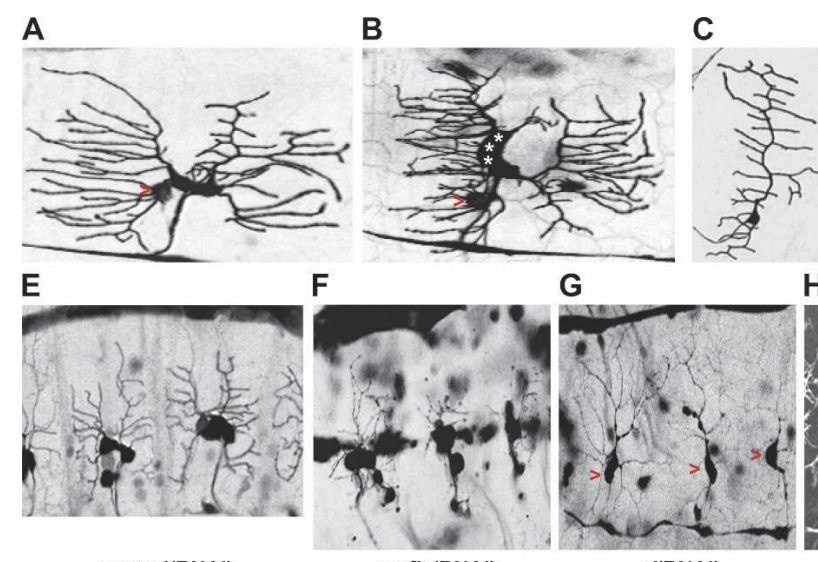

control(RNAi)

nerfin(RNAi)

ci(RNAi)
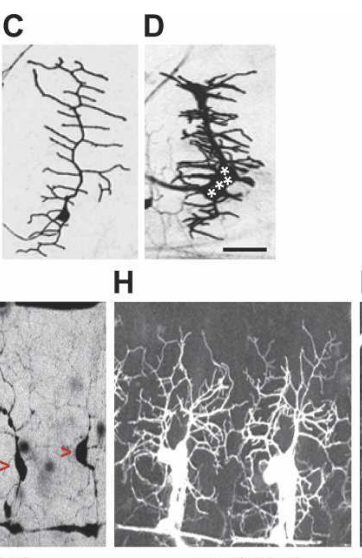

control(RNAi)

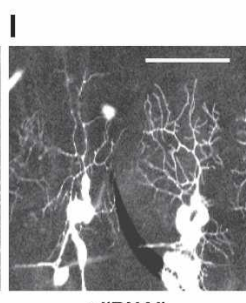

ci(RNAi)

Figure 6. Some TFs affecting class I da neuron number may also have post-mitotic effects on neuronal morphogenesis. $(A-D)$ Class I dendrites are unaffected by the number of class I neurons. $N^{t s} ;$ Gal4 $4^{221}$, UAS-mcd8::gfp embryos were grown at $25^{\circ} \mathrm{C}(A, C)$ or grown at $25^{\circ} \mathrm{C}$ with a 3 -h exposure to the nonpermissive temperature $\left(29^{\circ} \mathrm{C}\right)$ for $3 \mathrm{~h}$ beginning at $4 \mathrm{~h}$ AEL to induce neurogenic phenotypes $(B, D)$. Larvae were imaged live using confocal microscopy at $48 \mathrm{~h}$ AEL. $(B, D)$ The arborization patterns of dendrites from supernumerary class I neurons (denoted with white asterisks), which overlap extensively with one another, are similar to wild-type dendrites. $(B)$ The dendrites of the adjacent class I neuron is unaffected by the supernumerary neurons. $(A, B)$ The cell body of a class IV da neuron $(\mathrm{ddaC})$ that is also labeled by Gal4 ${ }^{221}$ is indicated with a red arrowhead. (E-G) Live image of class I dendrites in embryos injected with buffer control $(E)$, nerfin1 dsRNA $(F)$, or ci dsRNA $(G)$. ci(RNAi) causes a complete loss of dorsal class I da neurons, but the dorsal class IV da neuron (ddaC; indicated with red arrowhead) that is also labeled by Gal4 ${ }^{221}$ is still present. $(H, I)$ Live image embryo expressing GFP under the control of Gal4 ${ }^{109(2) 80}$, which is expressed in all md neurons, injected with buffer control $(H)$ or ci dsRNA $(I)$. Bar, $25 \mu$ m. 
not generally cause defects in arborization of neighboring class I neurons (data not shown). Therefore, analysis of class I neurons should allow us to study post-mitotic functions of genes that affect neuron number.

RNAi of several genes affected the number of class I neurons as well as morphogenesis of class I dendrites; RNAi of seven genes caused supernumerary cells and RNAi of four genes caused high penetrance cell loss in addition to dendrite defects (Fig. 6; Table 1). For example, RNAi of the zinc finger TF nerfin-1 caused an increase in neurons labeled by Gal4 ${ }^{221}$ with as many as eight neurons visible in some segments (Fig. 6F). Unlike wild-type class I neurons, neurons from nerfin-1(RNAi)-treated embryos extended mostly unbranched dendrites. In many cases, the routing pattern of the dendrites appeared abnormal, but the cell number defects make it difficult to resolve the projection pattern of individual dendrites or conclusively determine whether each neuron projects the same number of primary dendrites. RNAi of six other genes, including jumeau, a winged-helix TF known to regulate neuroblast cell fate and the number of PNS neurons, similarly caused an increase in neuronal number as well as defects in dendrite morphogenesis.

In addition to the seven genes that function to restrict class I neuron number and control dendrite morphology, three other genes are required to maintain the number of class I neurons. Reduction of their function caused a reduction of class I neurons and defects in dendrite morphogenesis in the remaining neurons (Table 1). For example, RNAi of the zinc finger TF senseless (sens) reduced the number of class I neurons, consistent with previous findings that sens is required for development of most cells in the PNS (Nolo et al. 2000). In addition, sens(RNAi) or a sens loss-of-function mutation caused an increase in dendrite outgrowth and mixing of dendrites in segments with both ddaD and ddaE present (see Figure 8, below). Similarly, RNAi of the proneural bHLH TF atonal (ato) reduced the number of class I neurons, consistent with previous findings that chordotonal organs and some md neurons are absent in embryos lacking ato (Jarman et al. 1993). Consistent with reports that ato functions in neurite arborization in the larval brain (Hassan et al. 2000), we also found that ato(RNAi) caused altered arborization patterns of class I dendrites. Thus, it is likely that multiple TFs that regulate neuron number also regulate aspects of post-mitotic neuronal differentiation.

Finally, we found one gene that appears to be essential for a subset of class I da neurons. RNAi of cubitus interruptus (ci), a component of the hedgehog signaling pathway, caused a loss of dorsal class I da neurons without affecting the ventral class I neuron vpda (Fig. 6G). Because ci(RNAi) causes embryonic lethality at high concentrations of dsRNA, the phenotypes in surviving embryos likely represent hypomorphic phenotypes. Loss of $\mathrm{ddaD}$ and ddaE is not compensated for by a concomitant increase in other md neurons since $c i($ RNAi) leads to an overall reduction of dorsal md neurons expressing the pan-da marker Gal4 ${ }^{109(2) 80}$ (Fig. 6H,I). Therefore, ci likely promotes differentiation or survival of a subset of da neu- rons, including ddaD and ddaE, but not of the ventral class I neuron vpda, demonstrating that morphologically similar neurons can be molecularly distinct.

\section{Reproducibility of RNAi screen}

To reduce the likelihood of identifying false positives and to determine whether different RNAi protocols yield different results, we have conducted multiple independent screens. Overall, each transcriptional regulator was represented in at least two, and as many as five, distinct screens, and the majority of positive candidates were isolated from multiple screens. Results from three screens with distinct injection protocols are depicted in Figure 7. The largest of these screens included 730 dsRNAs and yielded 64 positive candidates. The majority (33/42) of the candidates from the first screen that were represented in two subsequent screens were reisolated, demonstrating the reproducibility of this approach. At high concentrations of dsRNA ( $>5 \mathrm{mg} / \mathrm{mL})$, we observed an overall increase in embryonic lethality, and some candidate genes (e.g., brm and sna) identified from other screens were missed as a result of this lethality. On the other hand, three genes with substantial maternal contributions that were missed in other first screen (bonus, stat92e, and rpd3) were isolated when concentrated dsRNAs were used. Thus, in addition to genes that have essential early developmental functions or redundant functions in dendrite development, genes with large maternal contributions are the most likely candidates for false negatives from our screen.

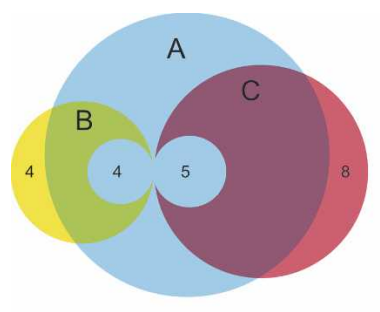

(A) Pools $1 \mathrm{mg} / \mathrm{mL}$ 730 TFs screened 64 candidates

(B) Single dsRNAs $5-10 \mathrm{mg} / \mathrm{mL}$ 144 TFs screened

(C) Single dsRNAs $1-2 \mathrm{mg} / \mathrm{mL}$ 336 TFs screened

Figure 7. RNAi-based analysis generates reproducible phenotypes. dsRNAs were injected individually (single dsRNAs) or pair-wise (pools) at different concentrations and assayed for effects on dendrite morphogenesis. (A) Following pair-wise injection of dsRNAs ( $1 \mathrm{mg} / \mathrm{mL}$ each) for $730 \mathrm{TFs}$, dsRNAs were subsequently injected individually from positive pools leading to the identification of 64 candidate genes. $(B)$ For a subset (144) of the $730 \mathrm{TFs}$, concentrated $(5-10 \mathrm{mg} / \mathrm{mL})$ dsRNAs were injected individually leading to the identification of 11 candidate genes (yellow circle), seven of which were also identified by screening the pools (yellow and blue overlap) whereas four were not. Four other genes identified from screening the pools did not yield reliable dendrite phenotypes when tested with injection of concentrated dsRNA, likely as a result of early lethality for at least two of the four genes (see text). (C) For a separate subset (336) of the $730 \mathrm{TFs}$, dsRNAs $(1-2 \mathrm{mg} / \mathrm{mL})$ were injected individually, leading to the identification of 34 candidate genes, of which 26 were previously identified from screening pools (red and blue overlap) and eight emerged only from screening dsRNAs individually. 
As one measure of confidence for our results, we analyzed known expression patterns for our candidates. Consistent with a function in neuron morphogenesis, 91\% (51/57; no expression data for other genes) of the candidate genes are expressed in the embryonic CNS and/or PNS (Supplementary Table S3). Genetic mutants have been isolated for 45 of the candidates, but only 24 of these have known functions in embryonic nervous system development. Finally, only one of the candidates, abrupt, has a known function in PNS dendrite development, while two other genes, ecdysone receptor and ultraspiracle, have been implicated in mushroom body dendrite development (Lee et al. 2000; Li et al. 2004; Sugimura et al. 2004). Almost all of these candidates are evolutionarily conserved and have at least one putative mammalian homolog (Table 2), raising the possibility that the majority of these genes function in conserved processes regulating dendrite morphogenesis.

To explore the possibility that the dendrite phenotypes result from defects in neighboring tissues such as the muscle and epidermis or reflect an overall defect in PNS development, we have carried out RNAi of candidate genes using GFP markers that label muscle, epidermis, or all md neurons. In addition, we analyzed the organization of the embryonic nervous system in mutant alleles of 40 of the candidate genes. In general, we found no correlation between any class of dendrite phenotypes and defects in muscle, epidermis, or nervous system morphogenesis, or md neuron number/position (Table 1). However, RNAi of several genes affected muscle, epidermis, and/or PNS organization (Table 1). For this subset of TFs, it remains to be determined whether they directly or indirectly influence dendrite morphogenesis. In general, mosaic analysis with genetic mutants will be required to unambiguously determine whether each of the TFs functions cell autonomously to regulate dendrite development.

\section{RNAi phenotypes of many candidates are confirmed by loss-of-function mutant phenotypes}

To assess the accuracy of our screen, we investigated whether RNAi phenotypes phenocopy loss-of-function mutants in candidate genes with available alleles. Mutant alleles of 27 of 32 genes analyzed affect da neuron development (Figs. 8, 9; Table 1). For most of these genes, mutant alleles yield qualitatively similar phenotypes as RNAi. For example, mutant alleles of snail or tramtrack caused dorsal overextension of primary dendrites as well as a severe reduction in lateral branching (Fig. 8B,C). Likewise, a worniu mutant allele caused overextension of primary dendrites and modest reduction of lateral dendritic branching (Fig. 8D). Embryos homozygous for a small deficiency spanning the nvy locus showed overextension of primary dendrites and an increase in overall branch number (Fig. 8E). Finally, approximately one of the two dorsal class I neurons was missing in most hemisegments in sens mutants (data not shown). In the remaining class I neurons, dendrites overextended dorsally and the arbors of $\mathrm{ddaD}$ and ddaE often mixed (Fig.
$8 F)$. In each of these cases, as well as several others, the RNAi phenotype produced a phenocopy of the mutant phenotype, demonstrating that our RNAi phenotypes accurately reflect loss-of-function phenotypes.

In some cases, the penetrance or timing of phenotypes in mutant alleles differs from those seen with RNAi, and alleles of five genes (brm, gro, tgo, Trap100, and trh) showed little or no effect on class I dendrite development. Strong loss-of-function alleles of two of these genes, groucho and the SWI/SNF homolog brahma, showed only mild defects in class I dendrite development, and strong maternal contributions have been reported for both of these genes. The only available allele of Trap100 is likely a hypomorph, and Trap100 is also likely maternally deposited (data not shown); further analyses will be required to determine whether maternal contributions provide the necessary functions each of these genes in embryonic dendrite development.

\section{Some TFs are continuously required to regulate class I} dendrite morphology

As another indication of the hypomorphic nature of many of the alleles and maternal rescue of gene function in mutant embryos, we focused on dendrite defects that were first apparent during larval stages (Fig. 9; data not shown). For example, a mutant allele of Drosophila Mi-2, which encodes a Hunchback-interacting ATP-dependant chromatin remodeling factor, shows only minor defects in late embryonic stages, but shows an obvious reduction in arborization by $72 \mathrm{~h}$ after egg laying (AEL) (Fig. 9B). Since $M i-2(R N A i)$ demonstrates that $M i-2$ is required for embryonic dendrite arborization, these findings suggest that $\mathrm{Mi}-2$ is continuously required for class I neurons to maintain proper dendrite arborization patterns. Similarly, the dendritic overbranching associated with a P-element insertion allele of $A d f 1$ was first apparent after embryonic stages, although $A d f 1$ (RNAi) caused overbranching in embryos. Class I dendritic arbors of Adf1 mutants are indistinguishable from wild-type neurons until 96 h AEL. By 144 h AEL, ddaE arbors of Adf1 mutants showed a greater than twofold increase in branch number when compared with time-matched wild-type controls (Fig. 9C,D). Interestingly, ddaD showed only very minor branching defects in Adf1 mutants, suggesting that $\mathrm{ddaD}$ and ddaE might have distinct requirements for Adf1. Similarly, mutant alleles of either $E(b x)$ or Elongin $C$ showed dendrite branching defects only at late larval stages (Fig. 9E; data not shown). These findings indicate that $A d f 1, E(b x)$, and Elongin $C$ are continuously required to inhibit branching in class I neurons, demonstrating that although class I neurons have very little new branching after embryogenesis, they still retain the capacity to branch.

\section{RNAi of some group A genes that cause reduced dendrite outgrowth and branching is epistatic to mutation of $a b$ or sens}

Since group A and B TFs regulate aspects of dendritic growth and branching, we wanted to explore potential 
Table 2. Transcriptional regulators of Drosophila dendrite development and their mammalian homologs

\begin{tabular}{|c|c|c|c|}
\hline Gene symbol & Gene name & Mouse homolog & Human homolog \\
\hline $\mathrm{ab}$ & abrupt & & \\
\hline acf1 & ATP-dependent chromatin assembly factor large subunit & BC065123 & BAZ1A \\
\hline \multicolumn{4}{|c|}{ alcohol dehydrogenase transcription factor 1} \\
\hline aop & anterior open & Etv6 & ETV6 \\
\hline $\operatorname{arc} 42$ & & Acads & ACADS \\
\hline asf1 & anti-silencing factor 1 & Asfla & ASF1A \\
\hline ato & atonal & Atoh1 & ATOH1 \\
\hline bap55 & Brahma-associated protein $55 \mathrm{kDa}$ & Actl6b & ACTL6B \\
\hline bap 60 & Brahma-associated protein $60 \mathrm{kDa}$ & Smarcd 3 & SMARCD3 \\
\hline bigmax & bigmax & Tcfl4 & TCFL4 \\
\hline bon & bonus & Trim 33 & TRIM33 \\
\hline brm & brahma & Smarca4 & SMARCA4 \\
\hline caf1 & Chromatin assembly factor 1 subunit & Rbbp4 & RBBP4 \\
\hline \multicolumn{4}{|c|}{ 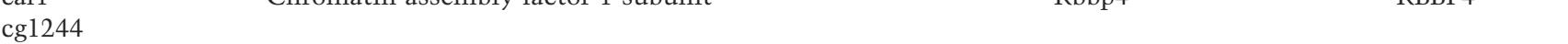 } \\
\hline $\operatorname{cg} 1841$ & & 1500005I02Rik & LOC388419 \\
\hline $\operatorname{cg} 1884$ & & Cnot1 & KIAA 1007 \\
\hline $\operatorname{cg} 2678$ & & & ZNF184 \\
\hline \multicolumn{4}{|l|}{$\operatorname{cg} 2808$} \\
\hline $\operatorname{cg} 4328$ & & Lmxlb & LMX1B \\
\hline $\operatorname{cg} 5343$ & & Gtl3 & GTL3 \\
\hline $\operatorname{cg} 5684$ & & Cnot7 & CNOT7 \\
\hline $\operatorname{cg} 7056$ & & Hhex & HHEX \\
\hline \multicolumn{4}{|l|}{$\operatorname{cg} 7417$} \\
\hline cg9104 & & Tusc 4 & TUSC4 \\
\hline $\operatorname{cg} 17118$ & & Gtl3 & GTL3 \\
\hline chm & chameau & Myst2 & MYST2 \\
\hline $\mathrm{ci}$ & cubitus interruptus & Gli3 & GLI3 \\
\hline D4 & & Dpf2 & DPF2 \\
\hline dpn & deadpan & Hes 1 & HES1 \\
\hline $\mathrm{E}(\mathrm{bx})$ & Enhancer of bithorax & Falz & FALZ \\
\hline $\mathrm{E}(\mathrm{z})$ & Enhancer of zeste & Ezh2 & $\mathrm{EZH} 2$ \\
\hline E2f & E2F transcription factor & $\mathrm{E} 2 \mathrm{f} 3$ & $\mathrm{E} 2 \mathrm{~F} 3$ \\
\hline EcR & Ecdysone receptor & Nr1h3 & NR1H3 \\
\hline elongin-C & Elongin $\mathrm{C}$ & Tceb1 & TCEB1 \\
\hline esc & extra sexcombs & Eed & EED \\
\hline $\mathrm{fd} 3 \mathrm{f}$ & Forkhead domain $3 \mathrm{f}$ & FOXA3 & FOXA3 \\
\hline $\mathrm{gcm} 2$ & Glial cells missing 2 & $\mathrm{Gcm} 2$ & GCM2 \\
\hline gro & groucho & Tle4 & TLE4 \\
\hline hmgD & High-mobility group protein D & Ssrp1 & SSRP1 \\
\hline iswi & Imitation SWI & Smarca5 & SMARCA5 \\
\hline jumu & jumeau & Foxn1 & FOXN1 \\
\hline kni & knirps & ROR & ROR \\
\hline $1(3) \mathrm{mbt}$ & lethal (3) malignant brain tumor & D930040M24Rik & L3MBTL4 \\
\hline lbe & ladybird early & Lbx1h & LBX1 \\
\hline M7 & $\mathrm{E}(\mathrm{spl})$ region transcript $\mathrm{m} 7$ & Hes1 & HES 1 \\
\hline M8 & Enhancer of split & Hes2 & HES2 \\
\hline mbf1 & multiprotein bridging factor 1 & Edf1 & EDF1 \\
\hline med21 & & LOC66172 & LOC400569 \\
\hline $\mathrm{Mi}-2$ & & Chd4 & CHD4 \\
\hline nerfin-1 & Nervous fingers 1 & IA-1 & INSM1 \\
\hline nvy & nervy & Cbfa2t $3 h$ & CBFA2T3 \\
\hline pcaf & & Gen512 & GCN5L2 \\
\hline ptx1 & & Pitx2 & PITX2 \\
\hline $\operatorname{Rpd} 3$ & & Hdac2 & HDAC2 \\
\hline RpS29 & & Rps29 & RPS29 \\
\hline run & runt & Runx1 & RUNX1 \\
\hline scrt & scratch & LOC383757 & SCRT2 \\
\hline sens & senseless & Gfil & GFI1 \\
\hline $\operatorname{Sin} 3 \mathrm{~A}$ & & $\operatorname{Sin} 3 a$ & SIN3A \\
\hline sirt2 & & Sirt2 & SIRT2 \\
\hline sna & snail & Snai2 & SNAI2 \\
\hline
\end{tabular}


Parrish et al.

Table 2. (continued)

\begin{tabular}{|c|c|c|c|}
\hline Gene symbol & Gene name & Mouse homolog & Human homolog \\
\hline snr1 & Snf5-related 1 & Smarcb1 & SMARCB1 \\
\hline sqz & squeeze & & LOC 149076 \\
\hline stat92e & & Stat5a & STAT5A \\
\hline $\mathrm{Su}(z) 12$ & Suppressor of zeste 12 & Suz12 & SUZ12 \\
\hline sv & shaven & Pax2 & PAX2 \\
\hline taf4 & TBP-associated factor 4 & 2610524B04Rik & TAF4B \\
\hline tgo & tango & Arnt & ARNT \\
\hline $\operatorname{trap} 100$ & & Thrap4 & THRAP4 \\
\hline trap36 & & Vdrip & MED4 \\
\hline $\operatorname{trh}$ & trachealess & Npas1 & NPAS1 \\
\hline ttk & tramtrack & & \\
\hline usp & ultraspiracle & Rxra & RXRA \\
\hline wor & worniu & Snai2 & SNAI2 \\
\hline $\mathrm{zf} 30 \mathrm{c}$ & Zinc finger protein at $30 \mathrm{c}$ & & \\
\hline
\end{tabular}

In many cases, multiple similar sequences were identified, and in those cases, the highest-scoring match is shown.

epistatic relationships among TFs in these phenotypic classes. To do this, we used RNAi to knockdown expression of select TFs in Drosophila embryos carrying a lossof-function mutation in either the group B/C gene senseless (sens) or the group A gene abrupt $(a b)$. As described above, sens mutant class I dendrites overextend dorsally and have reduced lateral branching in addition to routing defects (Fig. 8F) In sens mutants, RNAi of the group A genes $\operatorname{Su}(z) 12$ and $a b$, which cause increased lateral branching following RNAi in wild-type embryos, led to an increase in lateral branching compared with injected controls (Fig. 10A-C). Therefore, Su(z)12 and $a b$ function are still required to limit arborization in sens mutants, and the increased dendritic branching as a result of $\mathrm{Su}(z) 12$ (RNAi) or $a b$ (RNAi) is epistatic to the increased dorsal extension and reduced lateral branching of sens mutants. On the other hand, RNAi of the group A genes cg1244 and $\operatorname{cg} 1841$, which caused reduced arborization following RNAi in wild-type embryos, led to a reduction in primary dendrite outgrowth and lateral dendrite branching compared with injected controls (Fig. 10D,E). Therefore, at least in the instances described above, loss of group A genes is epistatic to loss of group B genes.

RNAi of group A genes either promoted or antagonized dendrite arborization; therefore, we wanted to determine the effect of simultaneously disrupting one group A gene that promoted and one group A gene that antagonized dendrite outgrowth and lateral branching. As described above, RNAi or a loss-of-function mutant of the group A gene $a b$ caused increased dendritic branching and extension of class I dendrites. In addition, mutation of $a b$ caused a significant reduction in the number of class I neurons labeled by Gal4 ${ }^{221}$ that was most pronounced in the dorsal cluster of PNS neurons, consistent with the results from our RNAi experiments. To facilitate epistasis analysis in $a b$ mutants, we have assayed for dendrite arborization effects in vpda, the ventrally located class I neuron. RNAi of the group A gene $h m g D$, which caused reduced primary dendrite outgrowth and reduced lateral branching when injected into wild-type embryos, caused a striking reduction in the number of dendritic branches and size of the receptive field of vpda in $a b$ mutants (Fig. 10F-G). RNAi of the group A gene bap55 had similar effects in $a b$ mutants (data not shown), demonstrating that, at least in some cases, loss of group A genes that results in reduced arborization is epistatic to loss of group A genes that results in increased arborization. Therefore it is possible that the different classes of group A genes antagonistically regulate a common set of target genes required for dendrite arborization.

\section{Discussion}

Conserved TFs regulate dendrite arborization, coordinate primary dendrite growth and lateral branching, and regulate dendrite routing

To investigate the role of TFs in regulating dendrite development, we have systematically reduced TF function in Drosophila using RNAi and monitored the effects on dendrite development in class I da neurons. We found

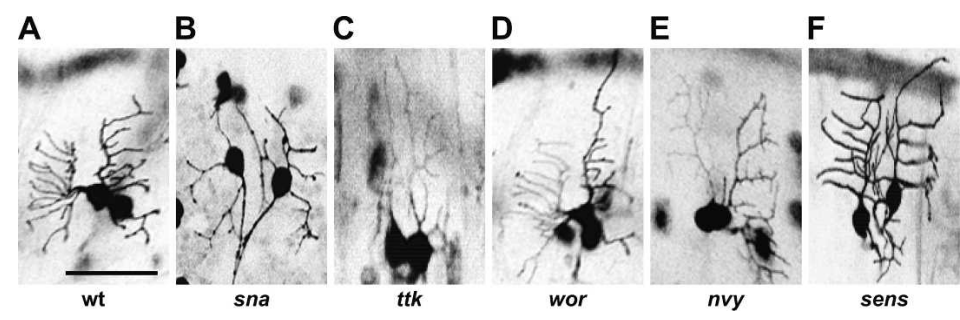

Figure 8. RNAi phenocopies loss-of-function dendrite phenotypes for many transcription factors. Representative images of class I neurons marked Gal4 ${ }^{221}$, UAS-mcd8::gfp for control $(A), \operatorname{sna}^{18}(B), t t k^{03 A}(C)$, wor $^{1}$ $(D), n y^{P D f K G-1}(E)$, and sens ${ }^{E 58}(F)$ homozygous mutant embryos at 17-18 h AEL. Bar, $25 \mu \mathrm{m}$. 

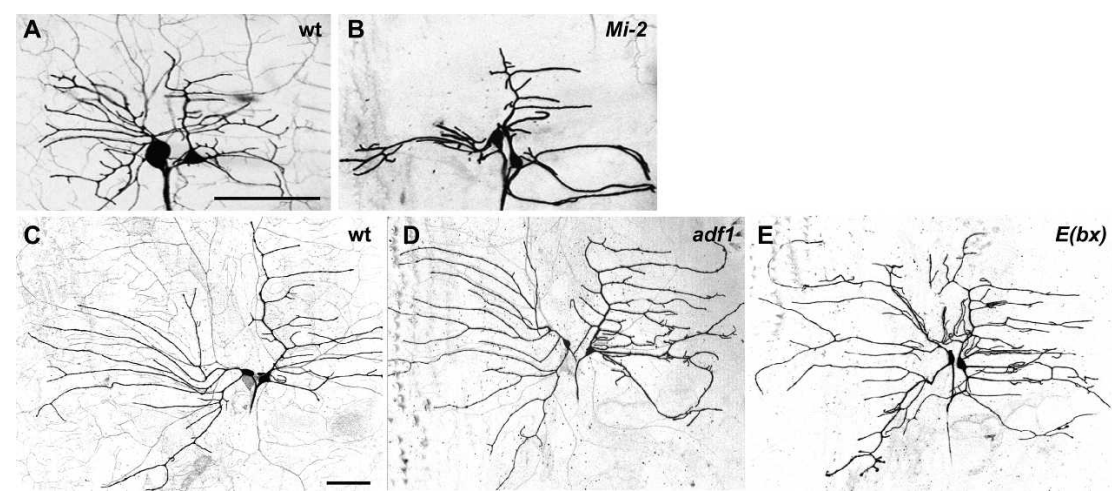

Figure 9. Requirement of certain transcription factors during larval development to maintain proper class I dendritic arbors. $(A, B)$ Live image of GFP-expressing class I dendrites in wild-type $(A)$ and a $M i-2^{j 3 D 4}$ homozygous mutant $(B)$ second instar larva (48 h AEL). (CE) Live image of GFP-expressing class I dendrites in wild-type $(C), \operatorname{Adf} 1^{01349}(D)$, and $E(b x)^{r y 122}(E)$ third instar larva. Bar, $50 \mu \mathrm{m}$. that $>70$ TFs play essential roles in the development of the stereotyped class I dendritic arbors. These TFs fall into three functional groups and hence provide insights about the underlying logic for dendrite development. Group A genes control both primary dendrite extension and branching, group B genes have opposing effects on primary branch extension and branching, and group $\mathrm{C}$ genes are required for proper routing of dendrites. Each of these genes is required for normal dendrite development during embryogenesis, and some of these genes continue to exert their influence over dendrite development beyond embryogenesis, after the basic dendrite patterns have been laid out. Most of these genes have not been implicated in dendrite development prior to this study, though most are expressed in neurons. Recently, it has been reported that $>300$ different TFs show restricted spatio-temporal expression patterns in the mouse brain (Gray et al. 2004). These TFs serve largely unknown functions in neural development, but given the fact that the majority of the TFs we have identified are evolutionarily conserved (Table 2), it should be possible to combine mouse expression analysis with our functional studies to identify candidate TFs that regulate the dendrite morphology of specific neuronal types in the mouse brain.

Interesting layers of regulatory mechanisms are likely under the control of the three groups of TFs, to specify overall dendritic growth, the balance between dendritic extension and branching, and dendritic placement. One large group of TFs (group A) has similar effects on both
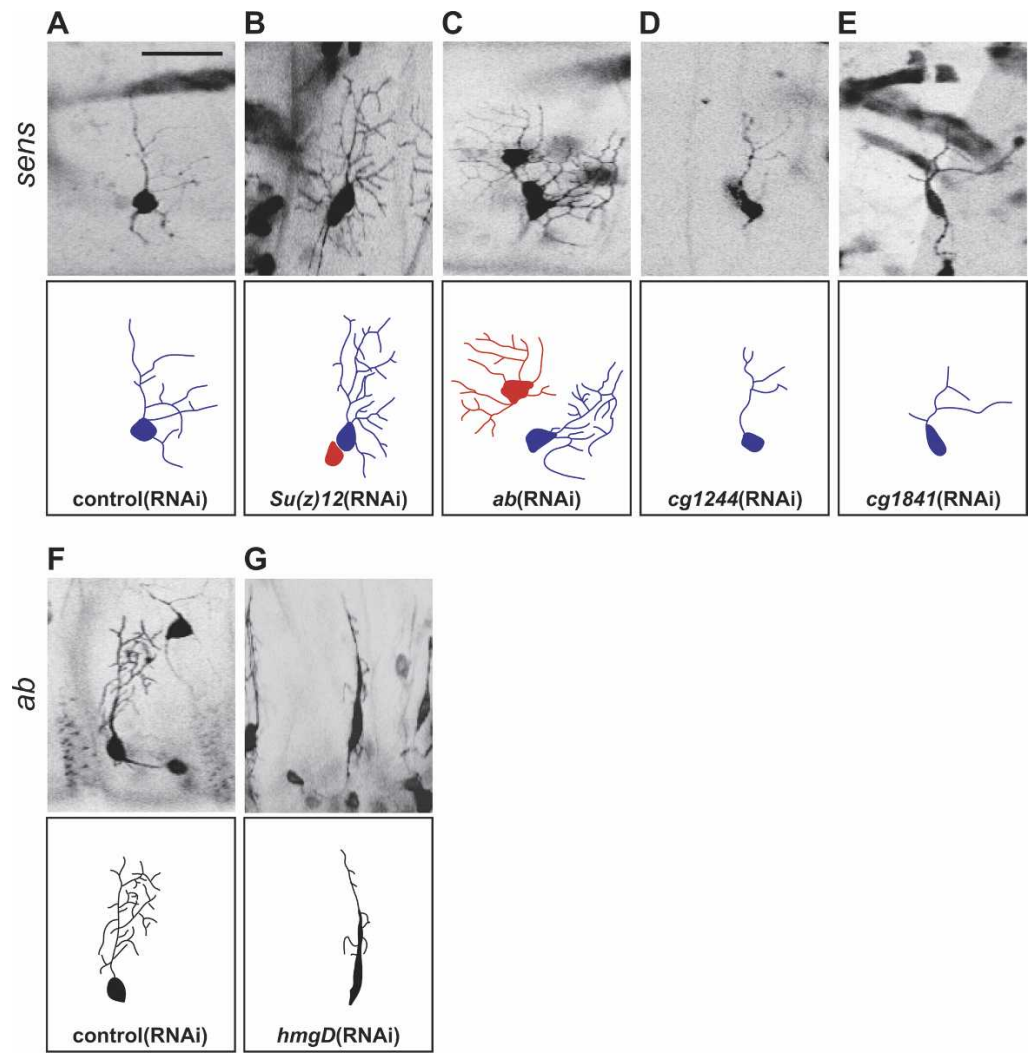

Figure 10. Epistatic interactions between group A and group $\mathrm{B}$ transcription factors. $(A-E)$ Live image and corresponding tracing of GFP-expressing dorsal class I dendrites in homozygous mutant $\operatorname{sens}^{E 58} \mathrm{em}$ bryos injected with buffer control $(A), \operatorname{Su}(z) 12$ dsRNA $(B), a b$ dsRNA $(C), c g 1244$ dsRNA $(D)$, or cg1841 dsRNA $(E) .(F, G)$ Live image and corresponding tracing of GFP-expressing ventral class I vpda dendrites in homozygous mutant $a b^{k 02807}$ embryos injected with buffer control $(F)$ or $h m g D$ dsRNA $(G)$. Bar, $25 \mu \mathrm{m}$. 
primary dendrite outgrowth and secondary branch extension, perhaps by regulating the basic building blocks of dendrite formation. A second group of TFs either enhance dendrite outgrowth at the expense of branching or vice versa (group B), demonstrating that, whereas these processes may utilize some of the same machinery, there are genetic programs that coordinate dendrite outgrowth with branching to limit overall dendrite growth and perhaps to temporally regulate dorsal versus lateral growth to conserve the total expanse of the dendrites. In addition to these TFs that regulate the branching pattern and dendrite length, we found that a third group (group C) is necessary for dendrite routing, presumably by interpreting positional cues and signals from surrounding cells.

\section{hox genes may contribute to regulation of dendrite arborization}

The functional links of several group A genes to hox genes suggest that hox genes may contribute to regulation of the extent of dendrite arborization. Among our candidates, $E(b x)$ and Iswi are components of the multiprotein nucleosome remodeling complex (NURF), which is known to be essential for expression of the hox gene ultrabithorax $(u b x)$ in eye imaginal discs (Badenhorst et al. 2002), and Su(z)12, esc, E(z), Rpd3, and Caf1 are components of the Esc/E $(z)$ silencing complex, which functions broadly to repress hox gene expression (Tie et al. 2001; Czermin et al. 2002; Muller et al. 2002) and other target genes. Another group A gene, nervy, is regulated by Ubx and is broadly expressed in neurons, suggesting that hox genes may function in neurons to regulate dendrite arborization (Feinstein et al. 1995). It thus appears that proper regulation of hox gene expression might be important for dendritic arborization.

\section{Coordination of primary dendrite growth and lateral branching involves transcriptional silencing}

Our phenotypic analysis of group B genes indicates that primary branch extension and lateral branch outgrowth at least partially antagonize one another. The majority of the group B genes function in transcriptional repression, suggesting that transcriptional repression is likely an important mechanism underlying this antagonism. Group B transcriptional repressors include TFs such as Tramtrack, Runt, and Groucho that mediate long-range repression involving histone deacetylation, which could be mediated by the Sin3a-Rpd3 deacetylase complex or possibly Sirt2, the Drosophila homolog of the yeast histone deacetylase Sir2. Furthermore, many of these genes may function together in a concerted pathway. For example, Tramtrack and Runt function together to establish repression of the segmentation gene engrailed and Runt recruits the corepressor Groucho to maintain this repression (Wheeler et al. 2002). Multiple components of the transcriptional Mediator (Med21, Trap100, and Trap36) were identified as group $\mathrm{B}$ genes and interactions between yeast Tup1 and C. elegans Unc-37, Groucho ho- mologs, and the Mediator suggest that recruitment of the Mediator may contribute to Groucho-mediated redendrite arborizationpression as well (Papamichos-Chronakis et al. 2000; Zhang and Emmons 2002). Therefore, target genes that normally promote outgrowth and limit branching may be targets of Groucho-mediated repression. Other group B TFs, such as Snail, Knirps, and the Snail-related TF Worniu, mediate short-range repression, which provides a way of silencing a particular enhancer of a target locus (Courey and Jia 2001). The use of multiple repressors could allow different sets of target genes to be repressed at different times or in response to different signals, and the use of both long-range and shortrange repressors could reflect a need for global regulation of some genes (long range) and more nuanced silencing of other genes in a particular place or time (short range). Taken together, the multiple repressors included among the group B genes allow for flexibility in regulation that may be required for proper coupling of dorsal dendrite outgrowth and lateral branching.

\section{What signals regulate class I dendrite routing?}

As with the number and length of class I dendritic branches, the position and direction of growth of class I dendrites are transcriptionally regulated. The ability of the primary dendrites of $\mathrm{ddaD}$ and $\mathrm{ddaE}$ to grow dorsally in parallel without crossing one another is controlled by different sets of genes, for nonoverlapping dendritic coverage and for proper orientation of dendrites. First, at least four genes (sens, bap55, cg1244, and cg7417) are necessary to prevent inappropriate crossing of $\mathrm{ddaD}$ and ddaE primary dendrites. In principle, the primary dendrite trajectory of ddaD and ddaE could be regulated by heteroneural repulsion that prevents the primary dendrites from crossing. However, class I dendrites are unaffected by removal of neighboring class I neurons or addition of supernumerary class I neurons. It thus seems likely that cues from other cell types contribute to the segregation of these dendrites. Second, several other genes ensure that $\mathrm{ddaD}$ and $\mathrm{ddaE}$ arborize the anterior or posterior portion of the hemisegment, respectively, perhaps by providing the secondary lateral branches with the capacity to respond to positional information along the AP axis. Third, our results indicate that the Brahma complex likely plays a key role in the dorsal routing of class I primary dendrites. Interestingly, the Brahma complex has been shown to regulate expression of decapentaplegic $(d p p)$ in wing imaginal discs (Marenda et al. 2004) and $d p p$ is involved in dorsalization during embryogenesis. Moreover, knirps(RNAi) also caused low penetrance dorsal routing defects, and knirps is required for $d p p$-mediated regulation of tracheal development (Chen et al. 1998). Thus, several links exist between TFs required for proper routing of class I dendrites and $d p p$.

\section{Additional applications for RNAi-based analysis of dendrite morphogenesis}

In this study we focused on transcriptional regulation of dendrite morphogenesis in class I da neurons. The RNAi 
screen developed in this study could potentially be adapted in future studies to address questions such as how different types of neurons specify their distinct arborization patterns. It is possible that the combined action of multiple TFs regulates the type-specific dendritic branching of different classes of md neurons. For example, highly branched neurons express high levels of Cut without expressing Abrupt, whereas md neurons with simple dendritic arbors express Abrupt but not Cut (Grueber et al. 2003a; Li et al. 2004; Sugimura et al. 2004). Furthermore, it is possible that a given TF functions differently in distinct neuronal types to regulate dendrite development. Our exhaustive analysis of transcriptional regulation of type I dendrite development provides an entry point to the analysis of type-specific dendrite development and provides a basis for comparison for similar studies in other systems.

\section{Materials and methods}

\section{Drosophila stocks}

We used Gal4 ${ }^{221}$, UAS-mCD8::GFP to visualize class I dendrites (Grueber et al. 2003a). Ga14 ${ }^{109(2) 80}$, UAS-GFP (Gao et al. 1999), and Wee-P26:GFP:Mhc (Clyne et al. 2003) flies are as described. Arm::GFPWeeP was kindly provided by Fabrice Roegiers (Fox Chase Cancer Center, Philadelphia, PA).

\section{dsRNA synthesis}

Putative regulators of transcription were identified based on gene ontology (GO) annotation. DNA templates (300-700 base pairs) for in vitro transcription were generated via two rounds of PCR, initially using gene-specific primers (Supplementary Table S1) with a $5^{\prime}$ GC-rich anchor (GGGCGG) and subsequently using a universal primer containing the T7 RNA polymerase promoter followed by the GC-rich anchor (Foley and O'Farrell 2004). dsRNAs were generated from these templates from in vitro transcription reactions carried out overnight at $37^{\circ} \mathrm{C}$ and were annealed by heating to $65^{\circ} \mathrm{C}$ and slowly cooling to room temperature. All products were tested for size and yield.

\section{Injection and RNAi screening}

Injections were essentially as described (Kennerdell and Carthew 1998). Embryos were collected on grape juice agar plates for $45 \mathrm{~min}$ at $25^{\circ} \mathrm{C}$, dechorionated for $2 \mathrm{~min}$ in $50 \%$ Clorox bleach, washed with distilled water, desiccated on double-sided tape, and covered with Halocarbon 95 oil. dsRNAs were injected into syncytial blastoderm embryos with RNasefree glass capillaries reaching to $\sim 50 \%$ egg length using a Picospritzer II (General Valve Inc.). Injected embryos were aged to stages 16 and 17 under oil at $18^{\circ} \mathrm{C}$ in a moist chamber, and dendrites in abdominal segments A2-A6 were imaged live with a Bio-Rad MRC600 confocal microscope. All dsRNA samples were coded; injection and screening were performed double blind.

\section{Time-lapse analysis}

First instar larvae were covered with $90 \%$ glycerol in PBS under a $50 \times 22 \mathrm{~mm}$ coverslip and then imaged on a Bio-Rad MRC600 confocal microscope. The larvae were recovered with forceps for further development until the next time point and were transferred to a grape juice agar plate.

\section{Acknowledgments}

We thank Edan Foley, Pat O'Farrell, Ron Vale, and Graehme Davis for dsRNA templates and advice on RNAi; Daniel Cox, Fabrice Roegiers, Rebecca Yang, and Susan Younger for fly stocks; the Bloomington and Szeged stock centers for fly stocks; and the Developmental Studies Hybridoma Bank for antibodies. We also thank the many laboratories that have provided fly stocks and antibodies for these studies, including Jurg Muller, Cristos Delidakos, Kryzysztof Jagla, John Tamkun, Alex Kolodkin, Ethan Bier, Andrew Dingwall, Susumu Hirose, J. Peter Gergen, Daisuke Yamamoto, Ruth Lehmann, Hugo Bellen, and Marcus Noll. Finally, we thank members of the Jan laboratory for helpful discussions. This work was supported by a Ruth L. Kirschstein NRSA post-doctoral fellowship to J.Z.P. and NIH grant R01 NS40929 to Y.N.J. L.Y.J. and Y.N.J. are Investigators of the Howard Hughes Medical Institute.

\section{References}

Ainsley, J.A., Pettus, J.M., Bosenko, D., Gerstein, C.E., Zinkevich, N., Anderson, M.G., Adams, C.M., Welsh, M.J., and Johnson, W.A. 2003. Enhanced locomotion caused by loss of the Drosophila DEG/ENaC protein Pickpocket1. Curr. Biol. 13: $1557-1563$.

Aizawa, H., Hu, S.C., Bobb, K., Balakrishnan, K., Ince, G., Gurevich, I., Cowan, M., and Ghosh, A. 2004. Dendrite development regulated by CREST, a calcium-regulated transcriptional activator. Science 303: 197-202.

Badenhorst, P., Voas, M., Rebay, I., and Wu, C. 2002. Biological functions of the ISWI chromatin remodeling complex NURF. Genes \& Dev. 16: 3186-3198.

Bier, E., Vaessin, H., Younger-Shepherd, S., Jan, L.Y., and Jan, Y.N. 1992. deadpan, an essential pan-neural gene in Drosophila, encodes a helix-loop-helix protein similar to the hairy gene product. Genes \& Dev. 6: 2137-2151.

Bodmer, R., Barbel, S., Sheperd, S., Jack, J.W., Jan, L.Y., and Jan, Y.N. 1987. Transformation of sensory organs by mutations of the cut locus of D. melanogaster. Cell 51: 293-307.

Brenman, J.E., Gao, F.B., Jan, L.Y., and Jan, Y.N. 2001. Sequoia, a tramtrack-related zinc finger protein, functions as a panneural regulator for dendrite and axon morphogenesis in Drosophila. Dev. Cell 1: 667-677.

Briscoe, J., Pierani, A., Jessell, T.M., and Ericson, J. 2000. A homeodomain protein code specifies progenitor cell identity and neuronal fate in the ventral neural tube. Cell 101: 435445.

Chen, C.K., Kuhnlein, R.P., Eulenberg, K.G., Vincent, S., Affolter, M., and Schuh, R. 1998. The transcription factors KNIRPS and KNIRPS RELATED control cell migration and branch morphogenesis during Drosophila tracheal development. Development 125: 4959-4968.

Clyne, P.J., Brotman, J.S., Sweeney, S.T., and Davis, G. 2003. Green fluorescent protein tagging Drosophila proteins at their native genomic loci with small P elements. Genetics 165: $1433-1441$.

Courey, A.J. and Jia, S. 2001. Transcriptional repression: The long and the short of it. Genes \& Dev. 15: 2786-2796.

Czermin, B., Melfi, R., McCabe, D., Seitz, V., Imhof, A., and Pirrotta, V. 2002. Drosophila enhancer of Zeste/ESC complexes have a histone $\mathrm{H} 3$ methyltransferase activity that 
marks chromosomal Polycomb sites. Cell 111: 185-196.

Dasen, J.S., Liu, J.P., and Jessell, T.M. 2003. Motor neuron columnar fate imposed by sequential phases of Hox-c activity. Nature 425: 926-933.

Dasen, J.S., Tice, B.C., Brenner-Morton, S., and Jessell, T.M. 2005. A hox regulatory network establishes motor neuron pool identity and target-muscle connectivity. Cell 123: 477491.

Ericson, J., Briscoe, J., Rashbass, P., van Heyningen, V., and Jessell, T.M. 1997. Graded sonic hedgehog signaling and the specification of cell fate in the ventral neural tube. Cold Spring Harb. Symp. Quant. Biol. 62: 451-466.

Feinstein, P.G., Kornfeld, K., Hogness, D.S., and Mann, R.S. 1995. Identification of homeotic target genes in Drosophila melanogaster including nervy, a proto-oncogene homologue. Genetics 140: 573-586.

Foley, E. and O'Farrell, P.H. 2004. Functional dissection of an innate immune response by a genome-wide RNAi screen. PLoS Biol. 2: E203.

Gao, F.B., Brenman, J.E., Jan, L.Y., and Jan, Y.N. 1999. Genes regulating dendritic outgrowth, branching, and routing in Drosophila. Genes \& Dev. 13: 2549-2561.

Gaudilliere, B., Konishi, Y., de la Iglesia, N., Yao, G., and Bonni, A. 2004. A CaMKII-NeuroD signaling pathway specifies dendritic morphogenesis. Neuron 41: 229-241.

Goldstein, A.Y., Jan, Y.N., and Luo, L. 2005. Function and regulation of Tumbleweed (RacGAP50C) in neuroblast proliferation and neuronal morphogenesis. Proc. Natl. Acad. Sci. 102: 3834-3839.

Gray, P.A., Fu, H., Luo, P., Zhao, Q., Yu, J., Ferrari, A., Tenzen, T., Yuk, D.I., Tsung, E.F., Cai, Z., et al. 2004. Mouse brain organization revealed through direct genome-scale TF expression analysis. Science 306: 2255-2257.

Grueber, W.B., Jan, L.Y., and Jan, Y.N. 2002. Tiling of the Drosophila epidermis by multidendritic sensory neurons. Development 129: 2867-2878.

- 2003a. Different levels of the homeodomain protein cut regulate distinct dendrite branching patterns of Drosophila multidendritic neurons. Cell 112: 805-818.

Grueber, W.B., Ye, B., Moore, A.W., Jan, L.Y., and Jan, Y.N. 2003b. Dendrites of distinct classes of Drosophila sensory neurons show different capacities for homotypic repulsion. Curr. Biol. 13: 618-626.

Hassan, B.A., Bermingham, N.A., He, Y., Sun, Y., Jan, Y.N., Zoghbi, H.Y., and Bellen, H.J. 2000. atonal regulates neurite arborization but does not act as a proneural gene in the Drosophila brain. Neuron 25: 549-561.

Ivanov, A.I., Rovescalli, A.C., Pozzi, P., Yoo, S., Mozer, B., Li, H.P., Yu, S.H., Higashida, H., Guo, V., Spencer, M., et al. 2004. Genes required for Drosophila nervous system development identified by RNA interference. Proc. Natl. Acad. Sci. 101: 16216-16221.

Jan, Y.N. and Jan, L.Y. 2003. The control of dendrite development. Neuron 40: 229-242.

Jarman, A.P., Grau, Y., Jan, L.Y., and Jan, Y.N. 1993. atonal is a proneural gene that directs chordotonal organ formation in the Drosophila peripheral nervous system. Cell 73: 13071321.

Jessell, T.M. 2000. Neuronal specification in the spinal cord: Inductive signals and transcriptional codes. Nat. Rev. Genet. 1: 20-29.

Kaminker, J.S., Canon, J., Salecker, I., and Banerjee, U. 2002. Control of photoreceptor axon target choice by transcriptional repression of Runt. Nat. Neurosci. 5: 746-750.

Kennerdell, J.R. and Carthew, R.W. 1998. Use of dsRNA-mediated genetic interference to demonstrate that frizzled and frizzled 2 act in the wingless pathway. Cell 95: 1017-1026.

Kim, Y.O., Park, S.J., Balaban, R.S., Nirenberg, M., and Kim, Y. 2004. A functional genomic screen for cardiogenic genes using RNA interference in developing Drosophila embryos. Proc. Natl. Acad. Sci. 101: 159-164.

Komiyama, T., Carlson, J.R., and Luo, L. 2004. Olfactory receptor neuron axon targeting: Intrinsic transcriptional control and hierarchical interactions. Nat. Neurosci. 8: 819-825.

Lee, T., Marticke, S., Sung, C., Robinow, S., and Luo, L. 2000. Cell-autonomous requirement of the USP/EcR-B ecdysone receptor for mushroom body neuronal remodeling in Drosophila. Neuron 28: 807-818.

Li, W., Wang, F., Menut, L., and Gao, F.B. 2004. BTB/POZ-zinc finger protein abrupt suppresses dendritic branching in a neuronal subtype-specific and dosage-dependent manner. Neuron 43: 823-834.

Liu, L., Yermolaieva, O., Johnson, W.A., Abboud, F.M., and Welsh, M.J. 2003. Identification and function of thermosensory neurons in Drosophila larvae. Nat. Neurosci. 6: 267273.

Livet, J., Sigrist, M., Stroebel, S., De Paola, V., Price, S.R., Henderson, C.E., Jessell, T.M., and Arber, S. 2002. ETS gene Pea3 controls the central position and terminal arborization of specific motor neuron pools. Neuron 35: 877-892.

Magee, J.C. 2000. Dendritic integration of excitatory synaptic input. Nat. Rev. Neurosci. 1: 181-190.

Marenda, D.R., Zraly, C.B., and Dingwall, A.K. 2004. The Drosophila Brahma (SWI/SNF) chromatin remodeling complex exhibits cell-type specific activation and repression functions. Dev. Biol. 267: 279-293.

Moore, A.W., Jan, L.Y., and Jan, Y.N. 2002. hamlet, a binary genetic switch between single- and multiple-dendrite neuron morphology. Science 297: 1355-1358.

Muller, J., Hart, C.M., Francis, N.J., Vargas, M.L., Sengupta, A., Wild, B., Miller, E.L., O'Connor, M.B., Kingston, R.E., and Simon, J.A. 2002. Histone methyltransferase activity of a Drosophila Polycomb group repressor complex. Cell 111: 197-208.

Nolo, R., Abbott, L.A., and Bellen, H.J. 2000. Senseless, a Zn finger transcription factor, is necessary and sufficient for sensory organ development in Drosophila. Cell 102: 349362.

Papamichos-Chronakis, M., Conlan, R.S., Gounalaki, N., Copf, T., and Tzamarias, D. 2000. Hrs1/Med3 is a Cyc8-Tup1 corepressor target in the RNA polymerase II holoenzyme. J. Biol. Chem. 275: 8397-8403.

Poulin, G., Nandakumar, R., and Ahringer, J. 2004. Genomewide RNAi screens in Caenorhabditis elegans: Impact on cancer research. Oncogene 23: 8340-8345.

Redmond, L., Oh, S.R., Hicks, C., Weinmaster, G., and Ghosh, A. 2000. Nuclear Notch1 signaling and the regulation of dendritic development. Nat. Neurosci. 3: 30-40.

Shirasaki, R. and Pfaff, S.L. 2002. Transcriptional codes and the control of neuronal identity. Annu. Rev. Neurosci. 25: 251281.

Shuin, T., Yamazaki, I., Tamura, K., Kamada, M., and Ashida, S. 2004. Recent advances in ideas on the molecular pathology and clinical aspects of Von Hippel-Lindau disease. Int. J. Clin. Oncol. 9: 283-287.

Sugimura, K., Yamamoto, M., Niwa, R., Satoh, D., Goto, S. Taniguchi, M., Hayashi, S., and Uemura, T. 2003. Distinct developmental modes and lesion-induced reactions of dendrites of two classes of Drosophila sensory neurons. J. Neurosci. 23: 3752-3760.

Sugimura, K., Satoh, D., Estes, P., Crews, S., and Uemura, T. 2004. Development of morphological diversity of dendrites 
in Drosophila by the BTB-zinc finger protein abrupt. Neuron 43: 809-822.

Terman, J.R. and Kolodkin, A.L. 2004. Nervy links protein kinase a to plexin-mediated semaphorin repulsion. Science 303: 1204-1207.

Tie, F., Furuyama, T., Prasad-Sinha, J., Jane, E., and Harte, P.J. 2001. The Drosophila Polycomb group proteins ESC and $\mathrm{E}(\mathrm{Z})$ are present in a complex containing the histone-binding protein p55 and the histone deacetylase RPD3. Development 128: 275-286.

Tracey Jr., W.D., Wilson, R.I., Laurent, G., and Benzer, S. 2003. painless, a Drosophila gene essential for nociception. Cell 113: 261-273.

Wheeler, J.C., VanderZwan, C., Xu, X., Swantek, D., Tracey, W.D., and Gergen, J.P. 2002. Distinct in vivo requirements for establishment versus maintenance of transcriptional repression. Nat. Genet. 32: 206-210.

Zhang, H. and Emmons, S.W. 2002. Caenorhabditis elegans unc-37/groucho interacts genetically with components of the transcriptional mediator complex. Genetics 160: 799803. 


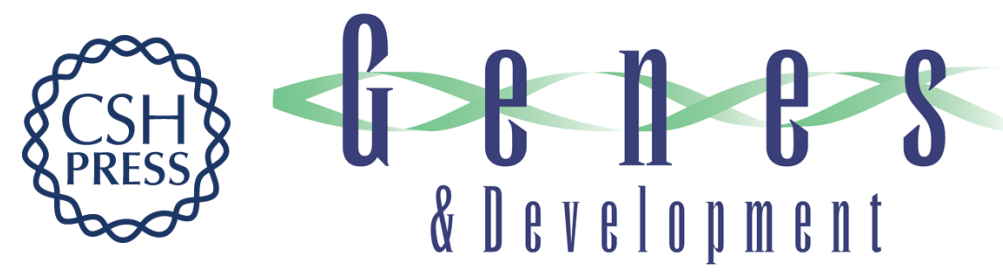

\section{Genome-wide analyses identify transcription factors required for proper morphogenesis of Drosophila sensory neuron dendrites}

Jay Z. Parrish, Michael D. Kim, Lily Yeh Jan, et al.

Genes Dev. 2006, 20:

Access the most recent version at doi:10.1101/gad.1391006

Supplemental
Material $\quad$ http://genesdev.cshlp.org/content/suppl/2006/03/16/gad.1391006.DC1

References This article cites 51 articles, 19 of which can be accessed free at:

http://genesdev.cshlp.org/content/20/7/820.full.html\#ref-list-1

License

Email Alerting Receive free email alerts when new articles cite this article - sign up in the box at the top

Service

right corner of the article or click here.

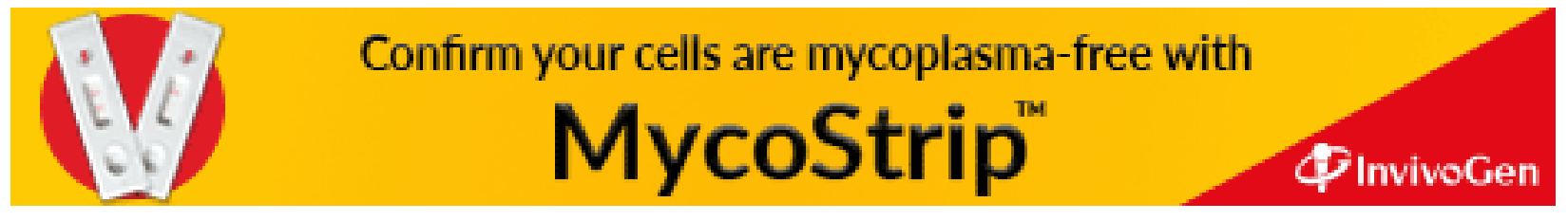

